\title{
Research and Practice of Characteristic Construction of Software Technology Specialty in Higher Vocational Education Based on Combination of School and Region and Integration of Department and Park
}

\author{
Yutai Rao ${ }^{1, a}$ and Fan Yang ${ }^{2, b^{*}}$ \\ ${ }^{1}$ Dean's Office, Hubei Radio \& TV University, Wuhan, Hubei, 430074, China \\ ${ }^{2}$ Department of Electrical and Information Engineering, Hubei Radio \& TV University, Wuhan, Hubei, \\ 430074, China \\ a2079406@qq.com, byangfan_sheep@163.com
}

Keywords: Combination of school and region; Integration of department and park; Software technology characteristic specialty construction

\begin{abstract}
At present, the problem of homogenization of software specialty in Higher Vocational Colleges in our country is serious, the same curriculum system, the same mode of personnel training, the training of software talents is universal. However, the imbalance of regional development, the size of the software companies, and the enterprise needs have their own focus, which requires the cultivation of software characteristics of professional personnel. This paper put forward the training model of school enterprise cooperation upgrade, from top to bottom to establish linkage mechanism, with the combination of school and region and the integration of department and park, so that higher vocational colleges can effectively cut regional development needs and the needs of enterprises, they can also do a professional characteristics, trained personnel can also meet the needs of a variety of software enterprises. This not only improves the system of Vocational Education in China, but also provides a feasible scheme for the cultivation of talents with other characteristics.
\end{abstract}

\section{Introduction}

Higher vocational colleges should closely cooperate with industry and research institutes to train the technical talents who serve the regional development, and focus on the technical research and development and product upgrading of service enterprises, especially small and medium enterprises. This requires that higher vocational colleges should grasp the needs of regional development, grasp the needs of enterprises. The traditional way of school enterprise cooperation in higher vocational colleges, only make them understand the present single needs of the enterprise, but for the whole industry and regional development needs of real-time and comprehensive understanding is not enough, and the talent quantity demanded by single enterprise is limited, which resulted in higher vocational colleges can cultivate universal talents. Universal talent refers to the needs of each enterprise, but can not fully meet the needs of enterprises.

The method proposed in this paper is to build a linkage mechanism with the combination of school and region and the integration of department and park, and to establish the linkage mechanism from top to bottom. The combination of school and region is the combination of school and regional development, the combination of school level and regional policy. The integration of department and park refers to the Department and the economic park, combined down throughout the cooperation of enterprise and specialty, so that the school can fully understand the needs of the enterprise, can cultivate the talents for the students to lay the foundation for high quality employment directly.

\section{Cooperation between Colleges and Enterprises}

The cooperation between colleges and enterprises is the most commonly used personnel training mode in higher vocational colleges, and there are many forms of cooperation between schools and enterprises. This is indeed a big step forward. However, this kind of school enterprise cooperation can 
not put the change of the industry to the teaching immediately, this change is reflected a considerable lag in the teaching. At the same time, under the background of the cooperation between schools and enterprises, the school still needs to spend a lot of manpower and material resources to study the enterprises every year, so as to adjust the specialty's curriculum system and training direction. The effectiveness and accuracy of the prediction of the demand for talents by schools and enterprises are also very limited, which restricts the development of high-quality talents and the development of new industries.

Almost all the higher vocational colleges will set up software technology specialty, have similar curriculum system and training direction, the graduates of software technology specialty is universal, on the surface they can meet the needs of any software job, but on a matter of fact, they often do not receive in the enterprise after they do not continue training. In fact, school enterprise cooperation has lost its fundamental significance.

\section{Upgrade Cooperation between Colleges and Enterprises}

In order to solve the above problems, this paper puts forward the consistent system of school enterprise cooperation, top-down linkage mechanism. School aspect, from the leadership level to the Department, from the Department to the specific specialty construction, each level can grasp the information in a timely manner, timely implementation of specialty construction.

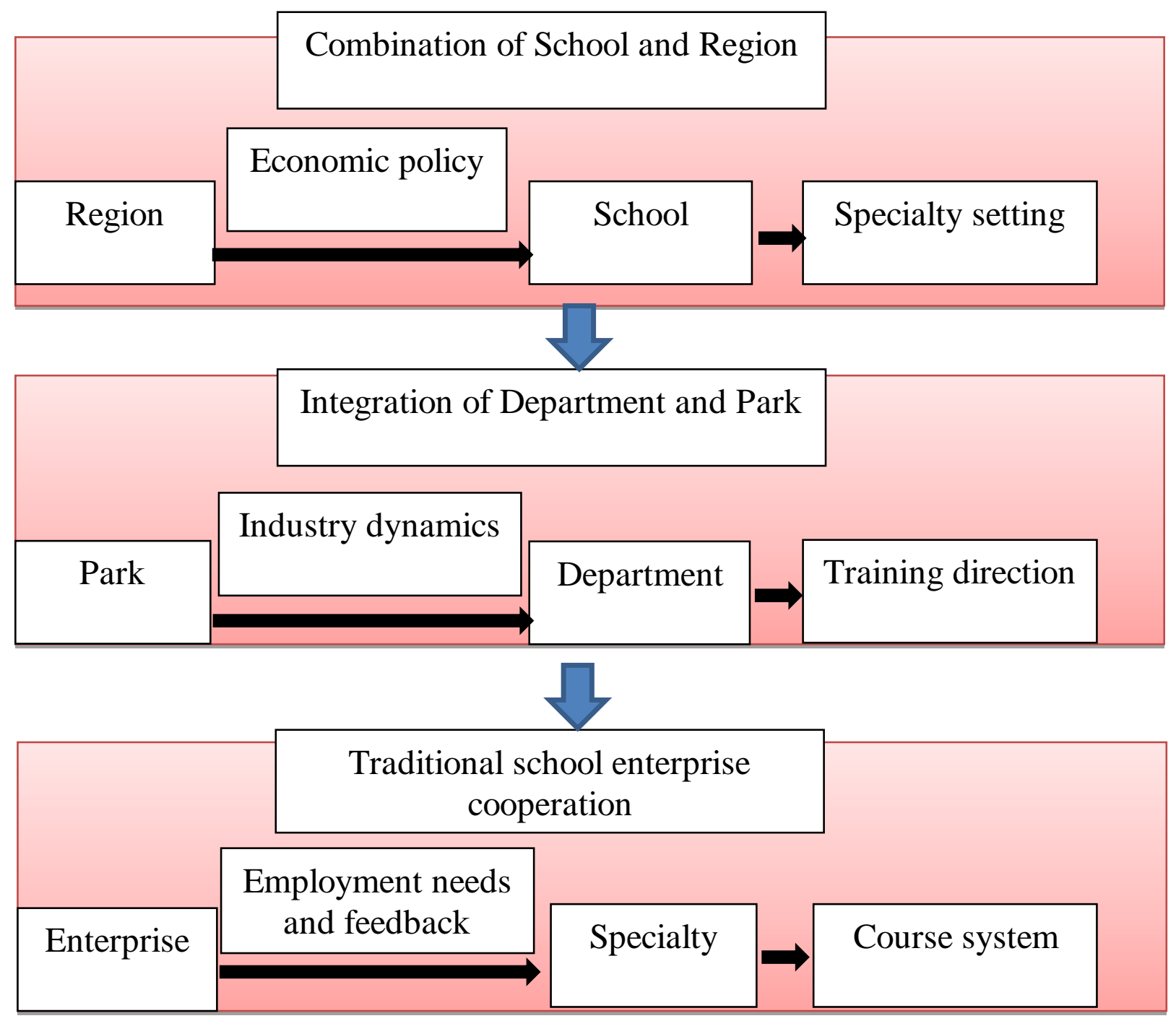

Figure 1. Upgrade Cooperation between Colleges and Enterprises 
Fig. 1 shows an upgraded version of the school enterprise cooperation structure. The upgraded version of the school enterprise cooperation is the combination of school and region and the integration of department and park mode, on the basis of the traditional mode of cooperation between schools and enterprises, two layers are expanded, and the task of each layer is different. At the top of the mode is the combination layer of school and region, this is a combination of economic development zones and schools, Economic Development Zone pass economic policies and documents to schools in a timely manner, the school makes specialty settings combined with their own. Specialty settings are including new specialty, closing specialty, adjustment, etc.. The combination of school and region ensures schools' important goal of serving local and developing regional economy. The second layer is the integration layer of Department and Park, this layer is the integration of high-tech park and department. High tech Park timely transfers of industry dynamics to the department. For example, the Department of software technology specialty should receive the software industry development zone from High tech Park, the department of the combination of their own practice sets the direction of specialty training, the direction of the training includes new, stop, adjust direction, etc.. The integration of Department and Park ensures the specialty service industry. The third level is the enterprise and professional cooperation layer, this layer is a number of enterprises in a high-tech park and professional cooperation, these enterprises timely delivery user needs and feedback information to the specialty, the specialty according to their own actual situation adjust the specialty curriculum system. Business and specialty cooperation ensures the accuracy of the course service positions.

Upgraded version of the school enterprise cooperation from top to bottom to improve the school enterprise cooperation system, three linkage mechanism maximizes the positive role of school enterprise cooperation, the function of the school enterprise cooperation is assigned to all levels of economic entities and teaching, the combination of peer to peer can be more efficient and more accurate cooperation.

Upgraded version of the school enterprise cooperation solves the following problems. First, it saves schools' manpower and material resources of specialty research, as well as time. Second, it avoids the problem of not decisive of the school specialty setting. Third, the direction of specialty training can be more suitable for the current needs not need to, no longer learn out of touch. Fourth, it cuts the course or curriculum content not need to, both to save the cost of teaching, but also to improve teaching efficiency. Fifth, it can be more targeted to carry out practical teaching. Sixth, it greatly shortens the time for graduates to truly become professionals.

The feasibility of upgraded version of school enterprise cooperation is very high, the policy of the government calls for strengthening integration of industry, University and research, enterprises and schools have their own needs for cooperation, therefore, the willingness of cooperation between the two sides is very high. Peer layer docking will not increase the original work, after the formation of cooperation system, production and learning can promote each other, forming a virtuous circle.

\section{Summary}

How to carry out school enterprise cooperation is a long-term task, how to give full play to the role of school enterprise cooperation is the need for long-term research and practice. After years of teaching practice, this paper comes to an upgraded version of the school enterprise cooperation, the aim is to obtain a more efficient culture method based on a simple and feasible model. Success specialty have specialty's characteristics, then specialty need to be able to serve the local economy, local economic development is characterized by specialty's characteristics. How to serve the local economy, the most fundamental way is to accurately grasp the needs of the local economy. After mastering demand, how to apply it to teaching, this requires a layer by layer conduction. Upgraded version of the school enterprise cooperation has initially solved these problems. The next step is specific to how to implement each of the specialty construction of the need for the characteristics. 


\section{Acknowledgements}

In this paper, the research was sponsored by the 2015 project of Hubei education scientific planning (Project No.2015GB347): Research and Practice on Higher Vocational Colleges Software technology Characteristic Specialty Construction Based on Combination of School and Region and Integration of Department and Park. Associate Professor Fan Yang of Hubei Radio \& TV University is the Corresponding Author of this paper, her email is yangfan_sheep@163.com.

\section{References}

[1] State Council of the PRC, Outline of the national medium and long term education reform and development plan (2010-2020), and 2008(2).

[2] Ministry of Education of the People's Republic of China, Some opinions on improving the teaching quality of Higher Vocational Education, 2006(16).

[3] Ministry of Education of the People's Republic of China, Opinions on strengthening personnel training in Higher Vocational Education, 2000(2).

[4] Development in Australia's vocational education and training system. NCVER2000, 2012-11-02.

[5] Dayuan Jiang, Theory and Practice on the legal construction of education occupation [J], Chinese Vocational and technical education,2012(9), p.14.

[6] Yu Liang, Peiyin Zhang, The practice of "four segment" talent training mode in Higher Vocational Colleges[J], Liaoning Higher Vocational Technical Institute Journal, 2013(1).

[7] Shuangying Lu, Whether China can contribute to its vocational education model [N], China Education Daily, 2014-2-25(5).

[8] Wenlong Cong, Research on the talent training mode of "four step progressive and work study combination" in Higher Vocational Education, Modern Education Science, 2012(3), p.96.

[9] Ronghui Wang, Hong Lv, Exploration on the talent training mode of combining work with study in Higher Vocational Colleges, Vocational Education Forum, 2012(18).

[10] Yunxia Chen, Research on the talent training mode of Higher Vocational Education [D], Lanzhou University, 2010.

[11] Minghua Ding, Reform and practice of innovative and entrepreneurial e-business talents training mode in Higher Vocational Colleges, Electronic Commerce, 2014(4).

[12]Zhanjun Li, A comparative study and Practice on the construction of teaching staff in China's Higher Vocational Education, Journal of Qingdao Technical College, 2013(2),p.33. 